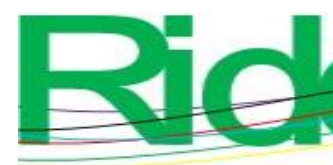

Revista lberoamericana para la Investigación y el Desarrollo Educativo ISSN 2007 - 7467

https://doi.org/10.23913/ride.v11i22.843

Artículos científicos

\title{
Estudio socioeducativo del caso de un profesor universitario en su historia de vida, en el arte, en sus albores y la academia
}

\author{
Socio-educational study of the case of a university professor in his life \\ history, in art, in its dawn and in the academy
}

Estudo socioeducativo do caso de um professor universitário em sua história de vida, na arte, nos primeiros tempos e na academia

Claudio Rafael Vásquez Martínez

Universidad de Guadalajara, México

crvasquezm@gmail.com https://orcid.org/0000-0001-6383-270X

Felipe Anastacio González González Universidad Autónoma de Tamaulipas, México

felgonzale@docentes.uat.edu.mx https://orcid.org/0000-0002-1410-8616

\section{Resumen}

El manejo de la noción del tiempo en la narración de vida es muy flexible, pues la sensación de temporalidad constituye una alternativa utilizada con plasticidad. Basándose en las descripciones de paisajes humboldianas, el objetivo de este estudio es narrar la historia de vida de un profesor universitario según su experiencia en el arte, en los albores de su historia de vida, en los contenidos de sus libros y en su experiencia como investigador, por lo que se ha usado una metodología de investigación cualitativa de historia de vida. La pregunta formulada fue la siguiente: ¿cuál es la historia de vida de un profesor universitario en sus lugares de trabajo? En este contexto, se presenta la razón estética cotidiana de elaborar sus trabajos, y se muestran sus aspectos socioeducativos, miedos, inquietudes, fantasías y 


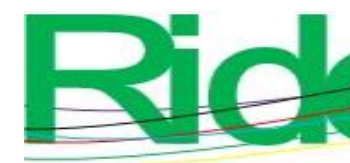

Revista Iberoamericana para la Investigación y el Desarrollo Educativo ISSN 2007 - 7467

resiliencias en cada uno de sus tópicos como creador de arte. Además, se manifiesta su muy particular trayectoria académica desde el punto de vista artístico.

Palabras clave: creador de arte, historia de vida, socioeducativo.

\section{Abstract}

The handling of the notion of time in the narrative of life is very flexible, the feeling of temporality constitutes an alternative used with plasticity. Based on the descriptions of Humboldian landscapes, the objective of this study is to narrate the life story of a university professor in his experience in art, at the dawn of his life history, in the contents of his books and in his experience as researcher where a qualitative life history research methodology is developed. To this end, the research question is the following: what is the life story of a university professor in their workplaces? In this context, the everyday aesthetic reason for developing their works is presented; showing his socio-educational aspects, his fears, concerns, fantasies and resilience in each of his topics as an art creator. In addition, the very particular academic trajectory from the artistic point of view is manifested.

Keywords: art creator, life history, socio-educational.

\section{Resumo}

O manejo da noção de tempo na narrativa da vida é muito flexível, uma vez que a sensação de temporalidade constitui uma alternativa utilizada com plasticidade. A partir das descrições das paisagens humboldianas, o objetivo deste estudo é narrar a história de vida de um professor universitário a partir de sua experiência na arte, o início de sua história de vida, o conteúdo de seus livros e sua experiência como pesquisador, para os quais foi usada uma metodologia de pesquisa qualitativa de história de vida. A pergunta feita foi a seguinte: qual a história de vida de um professor universitário em seu local de trabalho? Nesse contexto, é apresentada a razão estética cotidiana para o desenvolvimento de suas obras, e seus aspectos socioeducativos, medos, preocupações, fantasias e resiliência são evidenciados em cada um de seus temas como criador de arte. Além disso, sua carreira acadêmica muito particular se manifesta do ponto de vista artístico.

Palavras-chave: criador de arte, história de vida, socioeducativa. 


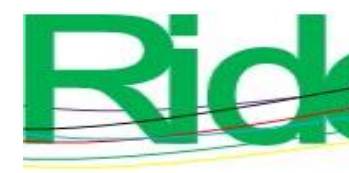

Fecha Recepción: Junio 2020
Revista Iberoamericana para la Investigación y el Desarrollo Educativo ISSN $2007-7467$

Fecha Aceptación: Enero 2021

\section{Introducción}

La identidad profesional es el extracto genuino de la entidad individual gestada en correlación a un lugar de trabajo y a un ambiente profesional de referencia, como es el caso del arte, la pintura, la enseñanza y la investigación. Son los albores de la vida, las huellas colocadas en el camino profesional, las ideas que el profesor trata de dar, así como las cosmovisiones en las diferentes facetas temporales cimentando materiales registrables para futuras generaciones. También puede verse como un fenómeno social de apropiación de esquemas que se conciben a partir de manejos eclécticos que incluyen rasgos sociales, académicos y artísticos.

La sensación de identidad inicia su configuración desde el nacimiento del individuo y se matiza con su autodesarrollo, con el entorno y, principalmente, con sus padres. Para este estudio, el profesor — como un personaje profesional— es en sí mismo una narración de su historia de vida basada en sus experiencias en el mundo del arte, sus publicaciones constantes y su capacidad como investigador, cumpliendo el objetivo de relatar su trayectoria como docente universitario en sus actividades cotidianas. Si bien la personalidad se piensa como una entidad que muestra una persistencia y duración en el tiempo, es importante enfatizar que toda historia de vida es el resultado de permanentes interacciones sociales, así como de la continua reinvención como ser humano.

El estudio de la identidad profesional de un profesor universitario da orientación a generar nuevas maneras de guiar, tanto en el contexto de pensamientos y mecanismos que si bien pueden ser idealistas también pueden verse como practicables en su totalidad. Toda historia de vida es meritoria, y el rol del profesor es, en consecuencia, digno de ser contado.

Aunado a lo anterior, la experiencia adquirida por el doctor Claudio Rafael Vásquez Martínez le permite observar en el arte una especial esencia, la cual es reflejada en sus obras, que llevan al espectador a un universo auténtico, donde toca la creatividad, la plasticidad, la estética y el trazo original en sus pinturas en óleo y acuarela. Su inspiración son los paisajes capturados en su mente durante los recorridos dinamizando amaneceres, atardeceres y anocheceres, como lo expone el estilo de Humboldt (1982).

En el aspecto de los albores del profesor Vázquez Martínez se contempla la creación de paisajes ecológicos y el paso del tiempo rápidamente: en su primaria, bachillerato y personajes que le impactaron en su expresión de colocar huella en sus actividades cotidianas. 

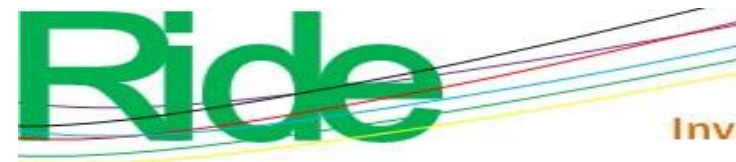

Revista Iberoamericana para la
Investigación y el Desarrollo Educativo
ISSN $2007-7467$

En lo tocante a sus publicaciones, realiza estudios en forma ex post facto, es decir, después del hecho, de analizar y describir los datos para hacer propuestas y mejoras continuas para la racionalización de las actividades académicas en las que ha participado.

Finalmente, en su experiencia como investigador comparte permanentemente sus conocimientos a través de la información que transfiere a sus estudiantes universitarios en la formación para futuras generaciones, mostrando sus realidades en el quehacer cotidiano.

\section{Objeto de estudio}

El objeto de estudio es describir la historia de vida de un profesor universitario en el arte, en sus albores y su experiencia como investigador.

\section{Objetivos}

- Explicar la historia de vida de un profesor universitario en sus lugares de trabajo.

- Especificar la experiencia en el arte de un profesor universitario en sus lugares de trabajo.

- Describir los albores de la historia de vida de un profesor universitario en sus lugares de trabajo.

- Describir la experiencia investigativa de un profesor universitario en sus lugares de trabajo.

\section{Hipótesis}

Existe la historia de vida de un profesor universitario en sus lugares de trabajo.

\section{Preguntas de investigación}

- ¿Cuál es la historia de vida de un profesor universitario en sus lugares de trabajo?

- ¿Cuál es la experiencia en el arte de un profesor universitario en sus lugares de trabajo?

- ¿Cuáles son los albores de la historia de vida de un profesor universitario en sus lugares de trabajo?

- ¿Cuál es la experiencia investigativa de un profesor universitario en sus lugares de trabajo? 


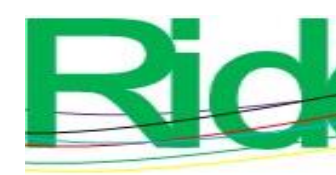

Revista Iberoamericana para la Investigación y el Desarrollo Educativo ISSN 2007 - 7467

\section{La experiencia en el arte}

$\mathrm{El}$ arte en el profesor tiene una especial esencia reflejada en sus obras, que llevan al espectador a un cosmos real, donde está tocado por la creatividad, la plasticidad, la estética y el trazo original que se convierte en virtud, porque es el que lleva el pincel a los recónditos lugares del óleo y la acuarela. Su búsqueda se involucra con sus recuerdos, con la mirada de masas de minerales, de formaciones rocosas, de masas de sólidos, líquidos y gases, con la manera, como esos componentes generales recorren en su historia de vida y en sus vivencias, valiéndose de imágenes como la mejor manera de interpretar la realidad del paisaje (Rivera, 2000).

Una esperanza, una parcela incontaminada de la condición humana es la que se palpa en su obra. Unas realidades que descubren la revelación, la epifanía, el deslumbramiento de algo intocado por él mismo, que puede ser la pureza y la estética perdidas; puede ser la esperanza de que no todo se ha destruido y aún hay mucho que contemplar. La estética a través del arte es la única salida que le queda al artista en sus diferentes manifestaciones de la naturaleza (Vásquez, 2000).

Su tránsito es la representación gráfica que no está siempre en las frases, pero sí dispuesta al abordaje de la belleza en las pinturas. Por eso su arte, sencillo y especial, queda en la fascinación de la memoria cuando terminan las palabras (Murillo, 1996).

Para acercarse a su trabajo es mejor aventurarse en sus creaciones: los cielos, la naturaleza, el arte bien equilibrado, porque son momentos indicados. El docente labora con un pensamiento de vida respecto al ambiente natural del cosmos, reflejándolo en un bosquejo de la naturaleza que trata de conservar un entorno homeostático del criterio y su entorno para implementar nuevas formas naturales y así resguardar a la naturaleza, conservando la homeostática del ámbito humanístico y la aportación de lo razonable en el crecimiento de la naturaleza a través de observar y analizar (Rivera, 2000).

El profesor sigue una corriente milenaria practicada en diversas culturas de los cinco continentes desde hace cientos de años. El expresionismo y el vanguardismo son estilos que se inspiran de la contemplación del paisaje y de la naturaleza. Es una ecopintura de reflexión y terapia, un instrumento para generar sensaciones de libertad, fraternidad e igualdad. Muchas de las pinturas realizadas se han tardado — en algunos casos - hasta 40 años para ser plasmadas, desde los bosquejos hasta su materialización en óleo o acuarela. 


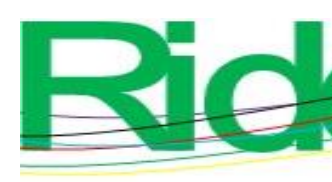

Revista Iberoamericana para la Investigación y el Desarrollo Educativo ISSN 2007 - 7467

Su obra está influencia por Claude Monet, Vincent van Gogh y Fernando Botero, lo que se evidencia en sus realizaciones de amaneceres, atardeceres y anocheceres. En su familia ha habido diferentes pintores Vásquez desde la época de la colonia.

Ha tenido exposiciones en Guadalajara (México), Puerto Vallarta (México), Pereira (Colombia), New York (New York), Phoenix (Arizona), Boston (Massachusetts), Salt Lake City (Utah), Long Beach (California), Seattle (Washington), Port Tobacco (Maryland), Sydney (Australia), Copenhaguen (Dinamarca), Puracé (Cauca), Honolulu (Hawái), Cambridge (Inglaterra), Sao Paulo (Brasil), Joahnnesburgo (Sudáfrica), Cape Town (Sudáfrica), Tokyo (Japón), Augusta (Maine), Washington D. C. (U.S.A.), Denver (Colorado), Charlottsville (Carolina del Norte), Bamberg (Alemania), Berlín (Alemania), Viena (Austria), Praga (República Checa), Sofía (Bulgaria), Varna (Bulgaria), Pomorie (Bulgaria), Borovets (Bulgaria), Plovdiv (Bulgaria), Nessebar (Bulgaria), Kyustendil (Bulgaria), Tryavna (Bulgaria), Beiging (República Popular China), Quito (Ecuador), Chicago (Ilinois), Salta (Argentina), Bogotá (Colombia), Sarajevo (Bosnia and Herzegovina), La Habana (Cuba), Cheongju (Corea del Sur), Tampere (Finlandia), New Orleans (Louisiana), Taiwan (Taiwan), Bangkok (Tailandia), Bandung (Indonesia), Buenos Aires (Argentina), Estambul (Turquía), Spokane (Washington), Miami (Florida), Frankfurt (Alemania), Duluth (Minnesota), Scranton (Pennsylvania), Knoxville (Carolina del Norte), Lincoln (Nebraska), Brimingham (Alabama), Rochester (New York), Tucson (Arizona), Hartford (Connecticut), Chapala (México), West Palm Beach (Florida), Tacoma (Washington), Katmandú (Nepal), St. Petersburg (Florida), Tucson (Arizona), Vancouver (Canadá), Eureka (California), París (Francia), Londres (Inglaterra), Mumbai (India), New Haven (Connecticut), Galveston (Texas), Madrid (España), Ciudad de Panamá (República de Panamá), Tlaquepaque (México), entre otros (Gómez-Aguiñaga, 2006).

Las representaciones de sus cuadros no se repiten, pues constituyen una contemplación espontánea de los colores primarios y secundarios y de las diferentes tonalidades que inspiran la naturaleza (Achinewhu-Nworgu, 2018). En cada una de sus pinturas inspira nuevos códigos ecológicos para que las personas se den cuenta de conservar y mantener el equilibrio ecológico, transmitiendo valores de esta índole en el registro de sus pinturas para colocar materiales registrables en futuras generaciones, para trascender en la protección de la ecología, plasmando paisajes naturales en escenas de amaneceres, atardeceres y anocheceres que se manifiestan en formas creativas e imágenes originales en la profunda contemplación de los hechos con resiliencia y empatía positiva (Vásquez, 2015). 


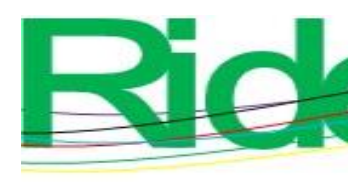

Revista Iberoamericana para la Investigación y el Desarrollo Educativo

ISSN 2007 - 7467

El profesor expresa formas de nuevos códigos para que la gente local y global se dé cuenta de la importancia de mantener la ecología, o por lo menos transmitir esos valores que se registran en sus pinturas para otras generaciones. En su familia, desde hace varias centurias se han dedicado a la pintura, y desde temprana edad ha pintado, publicando en los libros, revistas y bibliotecas del mundo, como la Biblioteca del Congreso de los Estados Unidos de América, Biblioteca de Luis Ángel Arango del Banco de la República de Colombia, Biblioteca Digital de la Universidad de Guadalajara, entre otras (Murillo, 1996).

El docente colabora con personas con discapacidad visual. Para detectar los colores sigue un camino basado en la apreciación con modelos en relieve. Así, los colores se codifican en números, los cuales quedan registrados en la imaginación para luego generar el paisaje. Como orientador motiva a la generación de propios códigos ecológicos según la creatividad de cada participante, los cuales realizan sus propias creaciones, popularizándolas e integrándolas, como el pensamiento de Friedrich Wilhelm Heinrich Alexander Freiherr von Humboldt, para integrar en las ciencias, el arte y las humanidades, tal como sucede en la realidad, en la naturaleza (Vásquez, 2008).

El profesor plantea que desde 1492 hasta 1992 fueron cinco siglos de dependencia. Pero ¿qué pasará en los próximos 500 años? ¿Seguiremos siendo dependientes o se generarán nuevas concepciones de representaciones ecológicas para que se identifiquen con los mejores y tener una visión estratégica igual o mejor que la de los países orientales? Ese es el propósito. No se puede quedar únicamente con el pensamiento de planear por sexenios o décadas para que las futuras generaciones vayan ideando y formando nuevas concepciones. La esencia de la vida y el crecimiento consiste en un permanente cambio dialéctico con visión resiliente positiva a pesar de los obstáculos (Ortiz, 2004).

Senderos intersticiales bordeados de árboles, ríos de lava serpenteando por las laderas, un árbol seco y retorcido con el satélite recorriendo cada uno de los espacios entre rama y rama son algunas imágenes que están plasmadas en sus pinturas para desarrollar la creatividad, disminuir el estrés y ayudar a personas con discapacidad visual, a niños con síndrome de Down y a quienes sufren adrenoleucodistrofia, enfermedad degenerativa mediante la cual se van perdiendo gradualmente los sentidos (Murillo, 1996).

Esta actividad artística es combinada con la deportiva, pues practica el lema de “mente sana en cuerpo sano". Desde hace 46 años ha ganado un total de 38 medallas en competencias celebradas en los cinco continentes, aunque afirma que lo importante de todo 


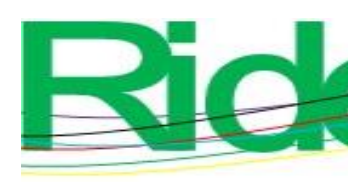

\section{Revista Iberoamericana para la Investigación y el Desarrollo Educativo ISSN 2007 - 7467}

esto es participar por buenas causas y ayudar a mejorar a las personas con grandes discapacidades (Murillo, 1996).

El profesor busca invitar al público a reflexionar sobre el entorno ecológico en que viven las personas, pues afirma que si no se tiene un justo medio o un equilibrio de esa distribución de la tecnología y la naturaleza, en lugar de avanzar la tierra se convertirá en un planeta con un paisaje desértico muy parecido al de Marte (Reyes, 11 de enero de 2006).

Esta pintura ecológica - fuera de ser revolucionaria - es reflexiva, contemplativa y además una filosofía de vida, como se ha observado desde sus ancestros. Estilos como el gótico, el renacentista, el barroco, el neoclásico, el expresionista — y ahora con esas grandes corrientes posmodernistas y de vanguardia - invitan a esa gran reflexión sobre el rescate de lo ecológico y de la pintura ecológica, la cual es coherente con una filosofía de vida que no solo se plasma en la pintura, sino que también se desarrolla en la práctica.

La formación interdisciplinaria que ha tenido con respecto a las áreas de humanidades, ciencias exactas, sociales, salud e ingenierías le han suministrado una gran riqueza de observación, ampliación, contemplación y estudio en cada una de las perspectivas y sombras que va realizando en cada una de sus pinturas, las cuales califica como una expresión sui generis. Es decir, cada pintura no se repite, pues - dice- es una contemplación espontánea en la que la riqueza de los colores primarios y de la naturaleza son prioritarios, ya que se dan formas definidas y consecuenciales, experienciales y secuenciales (Reyes, 11 de enero de 2006).

\section{Humboldt (1982) comentó:}

Yo estimo más adecuado, para los fines que persigo esta crónica de mi viaje, pintar el carácter específico que caracteriza a cada paisaje. Se conoce tanto mejor la fisonomía de una región cuanto más exactamente se captan sus diversos rasgos y se comparan entre sí; de este modo, por el camino del análisis, se va en busca de las fuentes del goce que nos depara el gran cuadro de la naturaleza (p. 22).

Observando a Humboldt (1982), se inspira en los paisajes pintados, en la quietud que se abre en las alturas, dorada cima que asciende hacia la luz. ¿Cómo se descansa en el agua, en su reflejo? ¿Cómo desciende la montaña en la quietud? La luz alza su vuelo y es un reitero de la aurora. La luz es un anuncio de palomas, que se remontan al volar el día. Algo se origina en los amaneceres, todo se dinamiza y se vuelve. Demasiadas crisis en muy poco tiempo, donde cada crisis es un riesgo y una oportunidad. Se hace la luz: es un nuevo día; la mirada 


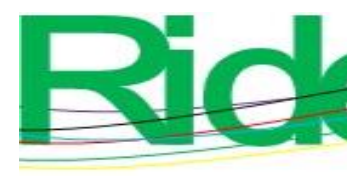

Revista Iberoamericana para la Investigación y el Desarrollo Educativo

ISSN 2007 - 7467

se orienta a los colores y algunas veces se avecinan nuevas imaginaciones creativas en las pinturas resilientes y empáticas. El astro rey enciende su altar y proporciona al día la mirada contemplativa en el infinito (Vásquez, 2019).

La luz que amanece es un renuevo de verde en las pupilas de los ojos para observar y pintar los paisajes ecológicos. El horizonte reaparece a las miradas, distanciándose de cada hecho para generar otros que se retroalimentan. Volcar el mañana para asumir en el interior del paisaje la mirada resiliente.

Planeando el horizonte, entreverando el aire con sus plumas, retiran las aves sus vuelos del paisaje. Al abrirse sus brazos y se alzan a la luz en brotes de silencio. Los cactus se manifiestan en los desiertos, el día se recorre sobre ellos sin ninguna prisa. La luz antes de irse sumerge su beso rojo en el ocaso. Los últimos matices de la tarde, conectan la mirada del paisaje en los anocheceres. Girones de luz en las pupilas desvanecen el sol en las exequias del día dinámico (Vásquez, 2018).

Danzan las nubes circundando el sol y entre rojizos brotes de color se transfigura el amarillo. El profesor, el escritor, el pensador y el artista los retienen en su memoria o los boceta en su agenda, en su estudio, los traduce con colores impetuosos, pinceladas maduras, construyendo esos paisajes en sus formatos, se convierten en retratos móviles que perduran sitios que el tiempo y las personas se encargan de transformar sus quehaceres, sus artes y sus estéticas (Vásquez, 1999).

Un anhelo, en una región libre de polución de la esencia humana es lo que se percibe en sus trabajos. Una realidad que se descubre es la manifestación, la señal, la iluminación de algo intocado por él mismo que puede ser la pureza y la estética perdida, puede ser la ilusión de que no todo se ha destruido y aún hay mucho que contemplar. La estética a través del arte es una salida que el artista propone desarrollando pintura ecológica paisajística y su aplicación en sus manifestaciones cotidianas que se encuentran en los diversos hechos de la naturaleza (Vásquez, 2017).

Observar, mirar, ver, contemplar los paisajes ecológicos es encontrar respuesta a la manera como debe enfrentarse la persona a la belleza de la naturaleza, con sorpresa y encanta, con sonrisa de todo el cuerpo, con la mirada cruzando el horizonte más allá de ella misma, porque lo que sigue es el arte en la estética. El arte en el profesor tiene una especial esencia reflejada en sus obras que llevan al espectador a un mundo que, aunque real, está tocado por la inspiración, la creatividad, la originalidad, la plasticidad, la estética y el trazo original que se convierte en virtud, porque es el que lleva el pincel a los recónditos lugares del óleo y la 


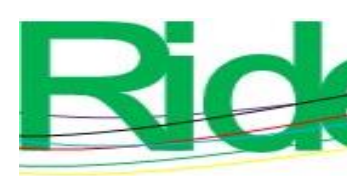

Revista Iberoamericana para la Investigación y el Desarrollo Educativo

ISSN $2007-7467$

acuarela. Su indagación se involucra con sus recuerdos, con la observación de masas de minerales, de formaciones rocosas, de masas de sólidos, líquidos y gases, con la manera como esos componentes generales pasean en su propia historia genealógica y en sus vivencias, valiéndose de imágenes creativas como la mejor manera de interpretar la realidad del paisaje ecológico. Los elementos se reúnen en combate, calor y color se mezclan revuelos de luz, se nutren de aire (Gómez-Aguiñaga, 2006).

Latencia de fuegos, ilusiones, pensamientos se van dando en los mensajes, manifestándose en los firmamentos. Las dimensiones de las mentes convalecen en los atardeceres. En el viento, hay flancos de nubes ondeando en silencio. Pliegos, nervaduras en las montañas, donde se sostienen los vegetales y en el vaivén de las tardes (Vásquez, 2019).

Andar, caminar en la contemplación de los árboles, se reúnen a cantar las aves con sus nidos, desplazando los rayos solares. Es el verde color que adquiere forma y presencia oscilatoria, donde se manifiesta con movimientos orgánicos. La sal en su movimiento va a estallar entre rocas, donde el mar en la tarde se invade de sonidos profundos. La nieve y la tierra se transforman. Los volcanes, más allá de las edades, se convierten en grandes relojes tectónicos. En el verde, donde se presenta con arrebato de mar y se encienden los atardeceres con sus rayos inmensos (Vásquez, 1999).

Unos instantes, antes de estallar el mar, se estremece entre el océano transformador. Los destellos de los astros reducen en la noche el firmamento. A un solo trazo de miradas de anocheceres, se alcanza a predecir una luz del sol. El calor termodinámico se ha despertado, observándose el amarillo que se ciñe de la nube y más allá en las estaciones de otoños, inviernos, primaveras, veranos. El silencio se ha extendido a lo largo. Le está esperando al final del camino, el carmesí que se vierte entre las flores. La sentencia de color es permanente. El día se vence entre las nubes en el inmenso paisaje ecológico. La transformación del paisaje, cae el temblor de las montañas con sus respectivos movimientos tectónicos. En el inicio verde de la mañana, el color se percibe, haciendo contacto con el día en la mirada contemplativa (Vásquez, 2000).

Se ahonda el día en los abismos con sus farallones inhóspitos. En una sensación de vacío los abismos se asoman del nadaísmo para contemplarlos en las probabilidades de sus existencias (Romero, 2009). El paisaje de bosque se conmueve, el verde se asoma en los relieves de la bruma. Entra el calor termodinámico, el grito de la tarde se sostiene en el furor de los árboles y se enciende el sol. La vía láctea, camino cósmico que se centra en el espacio, que interroga al silencio y se queda entre la noche jugando con los astros (Vásquez, 2015). 


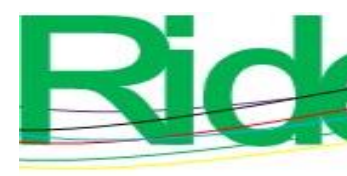

Revista Iberoamericana para la Investigación y el Desarrollo Educativo

ISSN 2007 - 7467

En el anochecer, se acumulan los sueños, verdeando el sendero y cambiando los cielos. El horizonte en la mar va a divulgar islas distantes destacándose más allá el confuso repunte del hábitat. Los accidentes geográficos no son solo suyos, son de todos los individuos. Ellos son del cosmos. Ellos serán del futuro mundo milenario. Las generaciones futuras disfrutarán de sus descubrimientos, de lo que hoy inspiran de la naturaleza, que lo rodea. La esencia de la vida aumenta, se transforma y cambia en los objetos sinergéticos que pinta en los estados sólido, líquido, gaseoso, permitiendo que sus representaciones sean lógicamente adecuadas, de modo que haya armonía en su pintura. Esa luz que se compone de muchas gamas de colores da esperanza en la vida, con empatía transformadora de dar sentido a la vida. El astro dorado, formas de amarillos, colabora en la fotosíntesis, nos prepara para las monedas en la madera, expresándose el marrón e hilvanando ciertas formas con el universo. En la vida los colores se reflejan en distintas tonalidades del mismo, con sus longitudes de onda captadas en nuestros ojos, en nuestros intelectos se vuelven imágenes originales (Vásquez, 2019).

Cada mancha que realiza es una expresión artística, donde cada uno de los códigos que plasma es una representación estética en los materiales de celulosa y cibernéticos para futuros hermenéuticos con visiones positivas para generaciones posteriores (Vásquez, 2017).

\section{Los albores}

Observando a Hagen (1962), se contempla en la creación de los paisajes ecológicos pintados. Parece que fue ayer, pues transcurrió el tiempo con una velocidad asombrosa. Su padre - doctorado con Medicina y Cirugía — doctor Fabio Vásquez Escobar, egresado de la Universidad de Antioquia, Medellín (Colombia). Comenzó su trabajo en Ebéjico (Antioquia) en 1956. Ese mismo año se casó con su madre, doña Amparo de los Dolores Martínez Vásquez.

Nació en Marinilla (Antioquia) el 22 de mayo de 1957. Sus padres, sus parientes Enoris Restrepo, Humberto Martínez, Rosmira Escobar, René Chardon, Fabio Antonio Martínez, Rodrigo Vásquez Escobar- con sus largas conversaciones y ejemplos lo orientaron para tener grandes visiones de intelectualidad, de escritura, de pensamiento de creación para generar materiales registrables en futuras generaciones. Sus padres le ayudaron a jugar con la pelota, a armar rompecabezas, a jugar ajedrez. En 1958 nació su hermano Juan José, con quien jugaba a escondidas, armaban rompecabezas y carros de juguetes. 


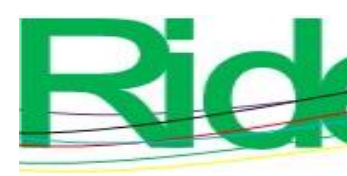

Revista Iberoamericana para la Investigación y el Desarrollo Educativo

ISSN 2007 - 7467

Sus padres les enseñaron a tender sus camas y les ayudaban en las tareas. Comenzaron a jugar futbol, basquetbol, voleibol, béisbol, tenis de campo, atletismo, ajedrez, ciclismo. Su padre les enseñó a jugar ajedrez durante muchas horas; él era un gran campeón en dicho deporte. De él aprendieron grandes jugadas del maestro José Raúl Capablanca y Graupera. Asimismo, se les inculcó la organización, la disciplina y el levantarse temprano para cumplir con las tareas de la escuela primaria, del bachillerato y de la universidad (Vásquez, 2018).

En la escuela urbana Marco Tulio Duque, El Carmen de Viboral, les enseñaron la limpieza de las bancas y los baños, así como a lavar los pies en el lavapatas y a escribir en los cajones de arena. Ahí aprendieron las primeras letras. Era una escuela pública de escasos recursos económicos: piso de barro y paredes de bareque, aunque de grandes ideas y resiliencias de todo lo que se observaba, desde los huertos escolares, las montañas del campo, los firmamentos con las diferentes figuras en las nubes y los fenómenos gaseosos.

Los colegas que estuvieron en la escuela Marco Tulio Duque fueron Francisco Giraldo, Bernardo Valencia, Uriel Cardona, Jorge Alberto Ossa Soto, Óscar Betancur, Juan Alonso Zuluaga, Alveiro Villa, Luis Alberto Acosta, Orlando Duque, Gustavo Orozco, Jesús Jaramillo, Hernando Betancur, Joaquín Giraldo, Jesús Daniel Pérez, Luis Jiménez, Francisco Hoyos, Alonso Giraldo, Francisco Cardona, Francisco Moreno, Álvaro Tobón y Luis Alberto Cardona, quienes se siguen reuniendo periódicamente para recordar sus anécdotas de historia de vida (Vásquez, 2017).

De ahí la inspiración en El Carmen de Viboral (Antioquia), donde estudió su primaria y bachillerato. Era, fue y es un clima que ayuda a la reflexión, la contemplación y el asombro para seguir con resiliencia positiva. El clima promedio en El Carmen de Viboral se halla entre los 18 y los 19 grados centígrados (Gaviria, 2000).

Ese ambiente favoreció para leer, pintar, observar y cumplir con las tareas del hogar: preparar la cama y darles de comer a las mascotas de su morada. Se cumplía con las asistencias y actividades escolares de matemáticas, ciencias naturales, geografía, deportes y otras. La jornada iba desde las 8:00 a. m. hasta las 5:00 p. m., de lunes a sábado.

En el bachillerato, participó en las ferias de la ciencia, y en el año 1975 ganó el primer puesto en la feria de la ciencia sobre un estudio de los quirópteros. Fue el mejor bachiller en la promoción de 1975 del Instituto Fray Julio Tobón Betancur (Fernández, 2017).

Siempre pintaba y observaba la pintura de sus ancestros: bisabuelos y abuelos. También veía la pintura de su madre hecha en el año de 1963 por el pintor P. Sabarrengo en una casa palacio donde vivía en la colonia de Buenos Aires (Medellín, Antioquia). 


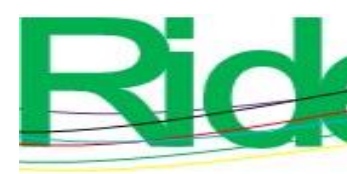

Revista Iberoamericana para la Investigación y el Desarrollo Educativo

ISSN 2007 - 7467

Igualmente, recolectaba rifas para ayudar a los colegas en la primaria y bachillerato. Había pocos recursos económicos, pero gran imaginación y resiliencia para seguir adelante en medio de las montañas, donde a las 6:00 de la mañana se despejaba de neblina, la cual cubría todo de nuevo a las 6:00 de la tarde (Robledo, 2007).

En las vacaciones se hacían largas jornadas de caminatas en las montañas y quebradas de la Cimarrona. Se caminaba por los túneles de piedra de las quebradas y túneles de barro en las montañas. Se abrían trochas en las montañas por sus espesas vegetaciones en compañía de amigas y amigos.

En primaria y parte de bachillerato fue acólito con distintos religiosos: padre Mario Ángel, padre Flavio Velázquez, obispo Gilberto Jiménez Narváez, obispo Óscar Aníbal Salazar Gómez, obispo Guillermo Escobar Vélez, obispo Gerardo Martínez Madrigal, padre Fabio Martínez, padre Salvador Jordán, quienes siempre le guiaron en sus labores académicas (Lalinde y Gaviria, 2004).

Los colegas que participaron en la promoción de bachillerato del Instituto Fray Julio Tobón Betancur fueron Francisco Giraldo, Rubén Darío Giraldo, Juan Alonso Zuluaga, Óscar Betancur, Alveiro Villa, Luis Alberto Acosta, Orlando Duque, Gustavo Orozco, Jesús Jaramillo, Jaime Giraldo, Hernando Betancur, Joaquín Giraldo, Jesús Daniel Pérez, Luis Jiménez, Francisco Hoyos, Francisco Cordona, Francisco Moreno, Blanca Tobón, Álvaro Giraldo, Luis Alberto Cardona, Adolfo León Ramírez y Pedro Trujillo.

Durante la primaria, bachillerato, universidad, así como en los viajes por los cinco continentes sus padres le inculcaron la idea para formar colecciones de láminas históricas, herbarios, paisajes, taxidermia, numismática, filatelia, libros, raquetas de tenis de campo, lepidópteros, coleópteros y rocas (Vásquez, 2017).

Además, sus padres le trasmitieron el gusto por la colección y recorte de periódicos, los cuales leía cuidadosamente, en especial sobre la historia de las ciencias. Como atleta, ha corrido varios maratones. Correr un maratón es especial y le cambia la vida en cada instante. Días antes del maratón está nervioso. Horas previas al maratón, duda sobre si su preparación ha sido la adecuada y si su alimentación ha sido la ideal para la distancia del recorrido. La noche previa al maratón se preocupa por levantarse temprano y llegar a tiempo a la salida de la competencia. Cuando suena el despertador, lejos de quedarse suplicando cinco minutos más de sueño, se levanta de inmediato para afrontar el reto. Durante los primeros kilómetros de la carrera se siente adaptado y va regulando los esfuerzos de la carrera. En el recorrido, observa a personas que no se administran bien y van abandonando la carrera. En cada lapso 


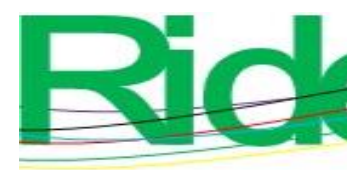

Revista Iberoamericana para la
Investigación y el Desarrollo Educativo
ISSN $2007-7467$

de recorrido hay socorristas, y se dan bebidas para la hidratación. En cierto punto de la carrera siente que va más lento, pero piensa positivamente en que puede alcanzar la meta. Al final, se pasa el resto del día descansando, se hidrata y tiene la satisfacción y el entusiasmo de haber terminado con resiliencia positiva el maratón recorrido (Vásquez, 2015).

Aunque nació en Colombia, tiene carta de naturalización como mexicano número 164/97, otorgada por el presidente Ernesto Zedillo Ponce de León en 1997. Se graduó como tecnólogo industrial y más tarde obtuvo la licenciatura en ingeniería industrial, así como la licenciatura en educación. Continuó con posgrados en universidades prestigiosas de Colombia, Estados Unidos de América y Estados Unidos Mexicanos. Obtuvo la especialización en relaciones industriales, magíster en sociología, especialización en recursos humanos, así como doctorado en educación universitaria. Igualmente, consiguió estudios de especialidad en matemáticas.

Actualmente vive en la ciudad de Puerto Vallarta. Tiene más de 40 años colaborando en el Club Rotario (Rotary International) realizado acciones de servicio comunitario y dando clases de ciencias humanísticas y de pintura en los cinco continentes (Vásquez, 2019).

\section{Los libros publicados}

Ha escrito 157 libros diferentes sobre pedagogía y enseñanza de la educación en ciencias (Vásquez, 2020). En estas obras explica procedimientos para realizar investigaciones ex post facto, es decir, para que después del hecho se analicen y describan los datos con el fin de hacer propuestas o iniciativas. De ese modo, se procura mejorar métodos actuales en los estudiantes para optimizar el rendimiento académico y evitar la deserción estudiantil.

El otro aspecto es la evaluación de medios y materiales, lo cual sugiere al docente para mejorar su material didáctico. Asimismo, les recomienda que escriban sobre sus áreas de trabajo, sus prácticas en el proceso de enseñanza-aprendizaje para hacerlo más dinámico. Igualmente, les sugiere que evalúen la administración con base en diferentes modelos, como el de Bertalanffy (1989), Anderson y Krathwohl (2001), Bloom (1981), Hastings (2016), Morris (1987), Provus (1971), Campbell (1999), Scriven (1995), Stufflebeam (2014), Suchman (1967), Taba (1974), Reiser (1996), Dick y Carey (2015), Stake (1999), los cuales ayudan a que sea más dinámico el proceso de la crítica, donde se toman los elementos más 


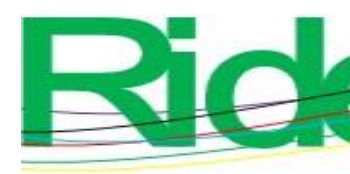

\section{Revista Iberoamericana para la Investigación y el Desarrollo Educativo ISSN 2007 - 7467}

políticos en la interacción del funcionamiento administrativo de un organismo o de una universidad.

Otro factor esencial tiene que ver con el impacto al personal administrativo, de servicios y de mantenimiento, los cuales también se deben mantener motivados para alcanzar los fines establecidos a corto, mediano y largo plazo (Scriven, 1995).

Además del impacto interno, es importante enfocarse en el impacto externo o de la sociedad, pues la institución se refleja en cada uno de los elementos constantes a nivel nacional y a nivel del exterior (Dick y Carey, 2015).

Otro de los aspectos básicos y prioritarios para el engrandecimiento de una institución es la investigación, la cual debe ser abordada desde su interior, su exterior y a nivel integrativo. Para esto, la universidad debe adecuarse y adaptarse a los factores tecnoeconómicos y políticos para diagnosticar sus problemas y generar un proceso de tres marcos: teórico, metodológico y analítico (Fitz-Gibbon, 2006). En el primero se documenta, en el segundo se emplean los instrumentos pertinentes para la evaluación de una universidad y en el último se confronta la teoría con la práctica para realizar una labor original y creativa que permita superar muchos impases (Morris, 1987).

\section{Experiencia como investigador}

Es investigador del Sistema Nacional de Investigadores del Consejo Nacional de Ciencia y Tecnología (SNI-Conacyt) (2019-2020) y consultor de la Unesco 1988 (Ortiz, 2004). Ha participado en congresos mundiales sobre investigación universitaria en Australia, Inglaterra, Francia, Alemania, Cuba, Rusia, Dinamarca, Indonesia, Finlandia, Estados Unidos de América, Brasil, Estados Unidos Mexicanos, Colombia, Ecuador, Argentina, Sudáfrica, India, Tailandia, Singapur, Corea del Sur, Bulgaria, China, Japón y otros países de los cinco continentes.

Reconocido a nivel mundial como una de las cinco mil personalidades del mundo por el Instituto Biográfico de Estados Unidos de América en 1996-1998 (Murillo, 1996). Obtuvo la distinción de profesor honoris causa en Bamberg, Alemania, en 1998. Doctor honoris causa por el Instituto de Estudios Tecnológicos y Superiores Matatipac, A.C., avalado por la honorable Academia Mundial de la Educación y por la Organización de las Américas para la Excelencia Educativa 2017. Premio Vallarta 31 de mayo 2019 (González, 1 de junio de 2019). 


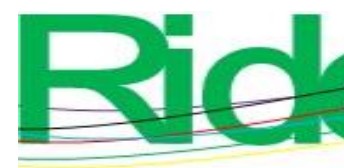

Revista Iberoamericana para la Investigación y el Desarrollo Educativo

ISSN 2007 - 7467

Actualmente, ejerce como profesor investigador universitario máxima categoría en la Universidad de Guadalajara, campus Centro Universitario de la Costa en Puerto Vallarta (Beltrán, 1 de junio de 2019). Por más de 45 años ha cumplido labores de investigación, docencia, tutoría, extensión, y ha sido director y sinodal de 46 tesis doctorales, 30 de maestría y 40 de licenciatura. En total, ha sido profesor de 3446 estudiantes universitarios (Ortiz, 2004).

\section{Metodología}

La presente es una investigación biográfica narrativa, pues el centro de interés es una historia de vida, así como la imagen de la experiencia de aspecto social. Este tipo de investigación se emplea como herramienta para comprender la identidad, los sentimientos y las experiencias del profesor universitario. El aspecto de esta investigación es la muestra educativa, artística y científica de las historias que se narran sobre el doctor Claudio Rafael Vásquez Martínez. Para este estudio, el aspecto personal es obligatorio para la comprensión social del profesor universitario.

En el estudio también se tratan relatos y documentos elaborados por otros investigadores acerca de las experiencias, acontecimientos, vivencias y hechos importantes de un profesor universitario (Anaya, 2015) para detallar —en este caso concreto - sus albores, sus publicaciones y su experiencia en el arte y como investigador.

La historia de vida es una metodología de investigación cualitativa, situada en el marco del denominado método biográfico (Rodríguez-Gómez, Gil-Flores y García-Jiménez, 1996), cuyo objeto principal es la transcripción y análisis que los investigadores realizan en fundamento de los relatos de un profesor universitario sobre su vida o momentos concretos de ella (Martín-García, 1995) y también sobre los relatos y documentos extraídos de terceras personas (Perelló, 2009).

\section{Resultados}

La idea principal sobre la identidad — que es la historia de vida de un profesor universitario - es una edificación del sí mismo como ser, como esencia del saber y hacer que se aprecia en las relaciones con los demás. Esto como resultado de sucesos sociales cotidianos que se revelan en el tiempo y se moldean en reciprocidad con la actitud de los individuos con 


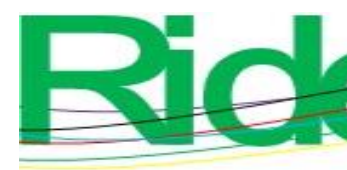

Revista Iberoamericana para la Investigación y el Desarrollo Educativo

ISSN 2007 - 7467

los que ha interactuado, y que se puede descubrir en otros su propia actitud y la actitud social en el ámbito universitario.

En este contexto, se presenta la razón artística y cotidiana del profesor al elaborar sus trabajos, con lo cual se muestran sus aspectos socioeducativos, miedos, inquietudes, fantasías y resiliencias en cada uno de sus tópicos como creador de arte.

El profesor realizó 531 pinturas paisajísticas ecológicas producto de 46 años de vida intelectual. Asistir a estos paisajes es encontrar la respuesta a la manera en que debe enfrentarse la persona a la belleza de la naturaleza, con sorpresa y encanto, con sonrisa de todo el cuerpo, con la mirada cruzando el horizonte más allá de ella misma, porque lo que sigue es el arte (Gómez Aguiñaga, 2006).

El miedo que más le impresionó fue cuando subió una montaña y un adulto mayor quiso agarrarlo. Fue tal el susto que comenzó a correr montaña abajo, a toda velocidad, con lo cual impidió que el adulto lo atrapara. Debido a esta experiencia, incursionó en el mundo del maratón, lo cual lo ayuda a mantener una condición física y mental ideal para no dejarse enredar.

El manejo de la noción del tiempo en su obra es muy flexible. La sensación de temporalidad constituye una alternativa utilizada con la flexibilidad; pasado y presente se mezclan sin que importe demasiado la solución de continuidad y sin separarse de elementos que han sido básicos en su cultura; parecería que busca redefinirlos, reconsiderarlos en este complejo nuevo milenio (Murillo, 1996).

Ha sido director y sinodal de 46 tesis doctorales, 30 de maestría, 40 de licenciatura. Ha sido profesor de 3446 estudiantes universitarios (Ortiz, 2004).

\section{Discusión}

El arte en el profesor tiene una especial esencia reflejada en sus obras que llevan al espectador a un cosmos real, donde está tocado por la creatividad, la plasticidad, la estética y el trazo original que se convierte en virtud, porque es el que lleva el pincel a los recónditos lugares del óleo y la acuarela. Su búsqueda se involucra con sus recuerdos, con la mirada de masas de minerales, de formaciones rocosas, de cuerpos sólidos, líquidos y gases, así como con la manera en que esos componentes generales recorren su historia de vida y sus vivencias, valiéndose de imágenes como la mejor manera de interpretar la realidad del paisaje (Rivera, 


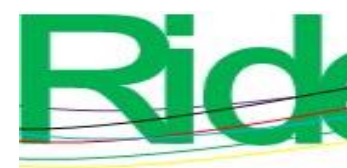

Revista Iberoamericana para la
Investigación y el Desarrollo Educativo
ISSN $2007-7467$

2000). Los elementos se reúnen en combate, calor y color que se mezclan en revuelos de luz y se nutren de aire (Gómez-Aguiñaga, 2006).

En la primaria le impresionó mucho la muerte de un amigo, Froylan Giraldo, quien iba con su novia cuando un extraño la empezó a piropear, lo que generó una disputa. Froylan se enredó en una bicicleta que había en la plaza principal de El Carmen de Viboral, y cayó de espaldas en el suelo. En ese momento, el contendiente sacó un puñal y lo apuñaló en el corazón. En segundos murió. Algo asombroso sucedió: la vida se fue en muy corto tiempo.

En cuanto a los estudios universitarios, nuestro autor ha señalado que se debe de tener en cuenta no solo el impacto hacia el estudiante, sino también hacia el profesor y su pensamiento pedagógico sobre la práctica que hace, pues existen diferentes formas de realizar esa praxis profesoral, de ahí la importancia de contar con una permanente retroalimentación (Stufflebeam, 2014).

\section{Conclusión}

Los aportes de este estudio muestran descubrimientos reveladores desde un enfoque de la identidad emocional del profesor universitario, lo cual va de la mano con las conceptualizaciones sobre su historia de vida en el arte, en sus albores y en su experiencia como investigador, además de la comprensión social pedagógica que le apasiona. La afinidad de estos aspectos es evidente, y las bondades del manejo ecléctico realizado sobre los diferentes enfoques resultan prometedoras. Asimismo, la experiencia que plasma en el ámbito práctico de la docencia es el bagaje de teorías obtenidas, de vivencias escolares, personales y profesionales. En todos los casos, su estilo muy propio en el quehacer educativo es digno de reconocerse, por lo que vale la pena hacer el esfuerzo por contar su historia de vida universitaria, su experiencia en el arte, así como la descripción de sus pinturas, la narración de sus libros aplicados a la educación y su experiencia como investigador en la formación de estudiantes universitarios para futuras generaciones, pues esto sirve para registrar aspectos estéticos, socioeducativos, miedos, inquietudes, fantasías y resiliencias que dan sentido a cada labor realizada. 

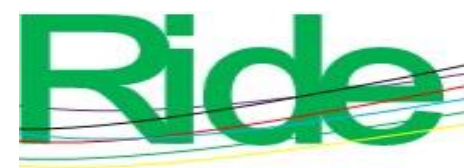

Revista Iberoamericana para la Investigación y el Desarrollo Educativo ISSN 2007 - 7467

\section{Futuras líneas de investigación}

De este estudio se desprenden futuras líneas de investigación:

- Estudios en aulas de clase en primaria, secundaria, preparatoria y universidad sobre historias de vida.

- Estudios locales en centros educativos sobre los efectos de las pandemias y el periodo de pospandemia con casos de resiliencia en historias de vida en sus integrantes.

\section{Referencias}

Achinewhu-Nworgu. E. (2018). An overview of integrating arts and creative practices to a business programme: QAHE in partnership with Ulster \& Northumbria Universities. Education in Modern Society, 16. 166-170.

Anaya, M. del C. (2015). Métodos y técnicas de investigación sociocultural. En Pérez, F., Ortiz, I., Domínguez, L. R., Cervantes, J. C., Olivera, A. R., Baños, J. A., Anaya, M. del C. y Ramírez, F. M. (eds.), Procesos metodológicos en ciencias sociales (pp.115144). Guadalajara: La Casa del Mago.

Anderson, L. W. y Krathwohl, D. R. (eds.) (2001). Taxonomía para aprender, enseñar y evaluar: una revisión de la taxonomía de Bloom de los objetivos. New York: Longman.

Beltrán, B. (1 de junio de 2019). Festejos de 101 años... celebran a Vallarta en sesión solemne de Ayuntamiento. Tribuna de la Bahía. Recuperado de https://tribunadelabahia.com.mx/noticias/puerto-vallarta/festejo-de-101-anoscelebran-a-vallarta-en-sesion-solemne-de-ayuntamiento-24889.

Bertalanffy, L. V. (1989). La teoría general de los sistemas. México D. F.: Fondo de Cultura Económica.

Bloom, B. (1981). Evaluación para mejorar el aprendizaje. New York: McGraw-Hill.

Campbell, D.T. (1999). Experimentación Social. Thousands Oaks, California: Publicaciones sabias.

Dick, W. y Carey, L. (2015). Diseño sistemático de instrucción. Boston: Pearson.

Fernández, J. C. (2017). Gentrificación en el Carmen de Viboral: una mirada sobre los múltiples procesos de urbanización que consolidan las fincas de recreo a partir de la 


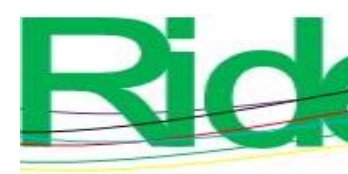

\section{Revista Iberoamericana para la Investigación y el Desarrollo Educativo ISSN 2007 - 7467}

inserción del capitalismo en el territorio (tesis de pregrado). Medellín: Universidad de Antioquía.

Fitz-Gibbon, C. T. (2006). Affective and behavioural Variables: Reforms as experimental to produce a civil society. Educational Psychology, 26(2), 303-323.

Gaviria, A. (2000). Municipios de mi tierra, El Retiro, La Ceja, El Carmen de Viboral, Oriente. Medellín: Editorial El Mundo.

Gómez-Aguiñaga, C. (2006). Filosofía de vida que desarrolla nuevos códigos ecológicos. Puerto Vallarta: Tribuna de la Bahía.

González, G. (1 de junio de 2019). Puerto Vallarta, 101 años de historia como municipio. Vallarta Opina.

Hagen, E. (1962). On the theory of social change. Homewood: Dorsey Press.

Hastings, J. (2016). A most enterprising country: North Korea in the Global Economy. Ithaca: Cornell University Press.

Humboldt, A. V. (1982). Del Orinoco al Amazonas. Barcelona: Editorial Labor S. A. Guadarrama. Punto Omega.

Lalinde, M. I. y Gaviria, D. L. (2004). Políticas de salud desde la perspectiva de los pobladores en el municipio del Carmen de Viboral (tesis de maestría). Medellín: Universidad de Antioquia. Facultad de Enfermería.

Martín-García, A. V. (1995). Fundamentación teórica y uso de las historias y relatos de vida como técnicas de investigación en pedagogía social. Aula, 7, 41-60.

Morris, L. L. (1987). Cómo comunicar los resultados de evaluación. Newbury Park, California: Publicaciones Sabias.

Murillo, C. (1996). Claudio Vásquez, investigador reconocido y pintor para una noble causa. Zapopan: Nexo Universitario.

Ortiz, L. (2004). Orgullo universitario, Claudio Rafael Vásquez Martínez. Guadalajara: Gaceta Universitaria. 6 de Diciembre. p. 36.

Perelló, S. (2009). Metodología de la investigación social. Madrid: Dykinson.

Provus, M. (1971). Discrepancy Evaluation. Berkeley, California: McCutchan, Pub. Corp.

Reiser, R. A. (1996). Planificación educativa: una guía para maestros. Boston: Allyn y Bacon.

Reyes, A. (11 de enero de 2006). Ecopintura, en busca de la reflexión sobre nuevos códigos ecológicos. Puerto Vallarta: Vallarta Opina 11.

Rivera A. (2000). Paisajes felices. Pereira: El Diario del Oton. 


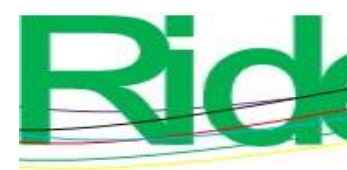

Revista Iberoamericana para la Investigación y el Desarrollo Educativo

ISSN 2007 - 7467

Robledo, G. L. (2007). La cerámica del Carmen de Viboral: un tesoro sin descubrir. Medellín: Universidad de Antioquia, Instituto de Estudios Regionales.

Rodríguez-Gómez, G., Gil-Flores, J. y García-Jiménez, E. (1996). Metodología de la investigación cualitativa. Granada: Aljibe.

Romero, A. (2009). Antología del nadaismo. Sevilla: Sibilina.

Scriven, M. (1995). The logic of evaluation and evaluation practice. New Directions in Evaluations, (68), 49-70.

Stake, R. E. (1999). Investigación con estudio de casos. Madrid: Ediciones Morata.

Stufflebeam, D. L. (2014). Teoría de la evaluación, modelos y aplicaciones. San Francisco: Jossey-Bass \& Pfeiffer Imprints, Wiley.

Suchman, E. A. (1967). Investigación evaluativa, principios y práctica en el servicio público y programas de acción social. New York: Russell Sage Foundations.

Taba, H. (1974). Elaboración del currículo. Buenos Aires: Editorial Troquel.

Vásquez, C. (1999). Evocación al paisaje. Pereira: Editorial Papiro.

Vásquez, C. (2000). Retrospectiva del arte de la pintura sobre la arquitectura paisajística. Pereira: Editorial Papiro.

Vásquez, C. (2008). Entrevista, Claudio Rafael Vásquez Martínez, coordinador del taller de Pintura del Centro Universitario de la Costa. Puerto Vallarta: Gaceta CUCOSTA.

Vásquez, C., González, F., Cardona, J. G., Betancourt, E. M., Hernández, G., González, I. C., González, A. G., Torres, V. J., Chavoya, J., Rendón, H., Flores, F., Franco, Y. (2015). Repercussions in brain hemispheres integration with image and text, through the use of information technology and paintings in their steps fractals. Puerto Vallarta: Impresos Alfa.

Vásquez, C., González, F., Alvarez, M. I., González, I. C., Betancourt, E. M., Rodríguez, S. E., Cisneros, D. M., Torres, J., Cardona, J. G., Zúñiga, L. M., Velazquez, J. N., Franco, Y., Rendón, H., Gutiérrez, S. M., Espino, P., Olaguez, J. E., Cabral, J., Peña, V., Morfin, M., Alvarez, M. (2017). The reorganization of the curriculum in educational cycles in CODEMA College: A positive step in paintings in their steps fractals. Zapopan: Arlequin Editorial.

Vásquez, C. (2018). Reflections on Educational Reforms in Latin America and painting in their steps fractals. Zapopan: Arlequin Editorial.

Vásquez, C. (2019). Poesía, paisajes sociopedagógicos y pinturas en etapas fractales. Zapopan: Arlequin Editorial. 


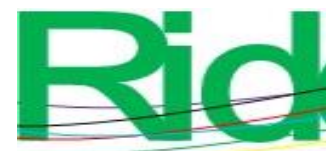

Revista Iberoamericana para la Investigación y el Desarrollo Educativo ISSN $2007-7467$

Vásquez, C., González, F. A., Flores, F., Guerra, M., Franco, Y., González, V. M., Alvarez, M. I., González, I. C., Betancourt, E. M., Rodríguez, S. E., Cisneros D. M., Torres, J., Cardona, J. G., Zúñiga, L. M., Rendón, H., Chavoya, J. I., Muñoz, H., Popov, N., Espino, P., Olaguez, J. E., Cabral, J., Alvarez, M., Anguiano, C. E. (2020).

Development of Careful, Creative and Critical Thought According to the Philosophy of Matthew Lipman; a proposal for inclusion in Basic Education and paintings in their steps fractals. Zapopan: Arlequin Editorial. 


\begin{tabular}{|c|c|}
\hline Rol de Contribución & Autor (es) \\
\hline Conceptualización & $\begin{array}{l}\text { Claudio Rafael Vásquez Martínez y Felipe Anastasio González } \\
\text { González. }\end{array}$ \\
\hline Metodología & $\begin{array}{l}\text { Claudio Rafael Vásquez Martínez y Felipe Anastasio González } \\
\text { González. }\end{array}$ \\
\hline Software & $\begin{array}{l}\text { Claudio Rafael Vásquez Martínez y Felipe Anastasio González } \\
\text { González. }\end{array}$ \\
\hline Validación & $\begin{array}{l}\text { Claudio Rafael Vásquez Martínez y Felipe Anastacio González } \\
\text { González }\end{array}$ \\
\hline Análisis Formal & $\begin{array}{l}\text { Claudio Rafael Vásquez Martínez y Felipe Anastasio González } \\
\text { González. }\end{array}$ \\
\hline Investigación & $\begin{array}{l}\text { Claudio Rafael Vásquez Martínez y Felipe Anastacio González } \\
\text { González }\end{array}$ \\
\hline Recursos & $\begin{array}{l}\text { Claudio Rafael Vásquez Martínez y Felipe Anastasio González } \\
\text { González. }\end{array}$ \\
\hline Curación de datos & $\begin{array}{l}\text { Claudio Rafael Vásquez Martínez y Felipe Anastacio González } \\
\text { González }\end{array}$ \\
\hline $\begin{array}{l}\text { Escritura - Preparación del } \\
\text { borrador original }\end{array}$ & $\begin{array}{l}\text { Claudio Rafael Vásquez Martínez y Felipe Anastasio González } \\
\text { González. }\end{array}$ \\
\hline $\begin{array}{l}\text { Escritura - Revisión y } \\
\text { edición }\end{array}$ & $\begin{array}{l}\text { Claudio Rafael Vásquez Martínez y Felipe Anastacio González } \\
\text { González }\end{array}$ \\
\hline Visualización & $\begin{array}{l}\text { Claudio Rafael Vásquez Martínez y Felipe Anastacio González } \\
\text { González }\end{array}$ \\
\hline Supervisión & $\begin{array}{l}\text { Claudio Rafael Vásquez Martínez y Felipe Anastacio González } \\
\text { González }\end{array}$ \\
\hline $\begin{array}{l}\text { Administración de } \\
\text { Proyectos }\end{array}$ & $\begin{array}{l}\text { Claudio Rafael Vásquez Martínez y Felipe Anastasio González } \\
\text { González. }\end{array}$ \\
\hline Adquisición de fondos & $\begin{array}{l}\text { Claudio Rafael Vásquez Martínez y Felipe Anastasio González } \\
\text { González. }\end{array}$ \\
\hline
\end{tabular}

